\title{
Analisis Kaizen dalam Meningkatan Produktivitas Penjualan Lobster Hidup (Panulirus Spp) di PT. Aruna Jaya Nuswantara Jakarta
}

\author{
[Kaizen Analysis in Increasing Productivity of \\ Lobster (Panulirus Spp) Sales at PT. Aruna Jaya Nuswantara Jakarta]
}

\author{
Nanda Anggiani Putri, Aef Permadi \\ Politeknik Ahli Usaha Perikanan Jakarta \\ Jl. Aup Barat Jl. Raya Pasar Minggu, RT.1/RW.9 • (021) 7806874
}

\begin{abstract}
Abstrak
Pemasaran mempunyai peran penting dalam pengembangan usaha perikanan. Di era yang serba digital banyak anak muda Indonesia yang tertarik membuat startup digital (Sociopreneurship) yang memanfaatkan teknologi sebagai platform telah dimanfaaatkan PT. Aruna Jaya Nuswantara untuk mengembangkan produk digital E-Commerce. Lobster yang dipasarkan dari beberapa Mini Plant PT. Aruna Indonesia, diantaranya yaitu Mini Plant Sorong, Berau, Kota baru, Balikpapan dan Kendari. Dari kelima Mini Plant tersebut, Mini Plant Kota Baru, Kalimantan Selatan merupakan Mini Plant yang paling produktif mengirimkan lobster terutama pada saat COVID-19. Tujuan penelitian yaitu untuk mempelajari, mengidentifikasi tahapan masalah dan menganalisa penyelesaian masalah penjualan lobster (Panulirus spp), dari Mini Plant Kota Baru di PT Aruna Jaya Nuswantara. Metode yang digunakan pada teknik permasalahan yaitu menentukan Key Performance Indicator, Fishbone Diagram, Analisa Root Cause dan Rencana Penerapan Intervensi. Total penjualan lobster (Panulirus spp), tingkat produktivitas dari lobster hidup sudah baik yakni diatas nilai 1 yang artinya jika kurang dari 1 adanya mengalami kerugian, Namun perlu adanya peningkatan untuk mencapai Key Performance Indicator yang telah ditetapkan, maka dari itu perlu di analisis intervensinya.
\end{abstract}

Kata kunci : lobster, kota baru, mini plant

\section{Abstract}

Marketing has an important role in the development of fisheries business. In the digital era, many young Indonesians are interested in creating a digital startup (Sociopreneurship) that utilizes technology as a platform has been utilized by PT. Aruna Jaya Nuswantara to develop E-Commerce digital products. Lobster marketed from several Mini Plant PT. Aruna Indonesia, including Mini Plant Sorong, Berau, Kota Baru, Balikpapan and Kendari. Mini Plant Kota Baru, South Kalimantan of five Mini Plants is the most productive Mini Plant to send lobsters especially during COVID-19. The purpose of the internship program is to study, identify the stages of the problem and analyze the problem solving of sales lobster (Panulirus spp), from the Mini Plant of Kota Baru at PT Aruna Jaya Nuswantara. The methods used in problem techniques are determining Key Performance Indicator, Fishbone Diagram, Root Cause Analysis and Intervention Implementation Plan. Total sales of lobster (Panulirus spp), the productivity level of lobster is well above the value which means that if less than 1 there is a loss, but there need to be an increase to achieve the Key Performance Indikator that has been set, therefore it is necessary to analyze the intervention.

Keywords : lobster, kota baru, mini plant 


\section{Penulis Korespondensi}

Nanda Anggiani Putri I nandaanggianiputri@gmail.com

\section{PENDAHULUAN}

Usaha perikanan adalah suatu sistem bisnis perikanan yang meliputi kegiatan pra produksi, produksi, pengolahan, dan pemasaran hasil perikanan. Pada prinsipnya usaha perikanan mencakup kegiatan usaha perikanan tangkap, perikanan budidaya, pengolahan hasil perikanan dan pemasaran hasil perikanan (Alma, 2011).

Pemasaran merupakan suatu proses yang membuat individu atau sebuah kelompok mendapatkan apa yang dibutuhkan dan diinginkan dengan menciptakan, menawarkan dan mempertukarkan produk yang berharga kepada pihak lain atau semua kegiatan yang menyangkut penyampaian produk atau jasa dari produsen sampai konsumen untuk mendapatkan keuntungan.

Pemasaran mempunyai peran penting dalam pengembangan usaha perikanan. Pemasaran merupakan ujung tombak keberhasilan suatu unit usaha dalam upayanya untuk menjual dan meningkatkan nilai usaha di mata konsumen terhadap produk atau jasa yang dihasilkannya. Bahkan keberhasilan suatu unit usaha ditentukan oleh keberhasilan pemasarannya (Kotler, 2012).
Kaizen

(continuous improvement) atau perbaikan berlanjut adalah aktivitas perubahan yang dilakukan secara terus menerus untuk meningkatkan apa yang telah dicapai ke arah yang lebih baik. Metode kaizen mengakar dari budaya perusahaan Jepang yang mengutamakan penyempurnaan dan perbaikan berkelanjutan yang melibatkan seluruh anggota perusahaan dengan menciptakan cara berfikir yang tidak hanya berorientasi pada hasil tetapi pada proses dan sebuah sistem manajemen yang menunjang serta menghargai usaha karyawan demi penyempurnaan. Pada dasarnya setiap individu maupun perusahaan manapun pasti menginginkan selalu menjadi yang terbaik, untuk itu perbaikan dan penyempurnaan setiap saat selalu diperlukan. Penyempurnaan yang dimaksud adalah menyempurnakan standar, berarti menetapkan standar lebih tinggi. Setelah tercapai standar tersebut, menjadi tugas manajemen untuk memelihara agar standar tersebut diterapkan (Wijaya, 2018).

$\mathrm{Di}$ era yang serba digital banyak anak muda Indonesia yang tertarik membuat startup digital (Sociopreneurship) yang 
memanfaatkan teknologi sebagai platform telah dimanfaaatkan PT. Aruna Jaya Nuswantara untuk mengembangkan produk digital $E$ Commerce. PT. Aruna Jaya Nuswantara adalah perusahaan yang termasuk dalam jenis sosial enterprise, yaitu suatu usaha dalam menyeimbangkan aspek bisnis dan aspek sosial dalam suatu kesempatan. Secara idealnya sosial enterprise tidak hanya mencari untung namun juga memberikan dampak pada lingkungan dan masyarakat. Inovasi yang diberikan yaitu perusahaan ini fokus pada sektor perikanan dengan langsung melakukan pendampingan pada nelayan di desa pesisir untuk meningkatkan kesejahteraan masyarakat pesisir. Kegiatan ini dijalankan dengan visi dan misi untuk mampu membuat ekosistem digital pada masyarakat pesisir dengan memperjelas setiap perannya. Saat ini, PT. Aruna Jaya Nuswantara sebagai platform e-commerce Business to Business (B2B) telah menghubungkan ribuan nelayan ke pabrik pengolahan hasil laut dan pembeli skala besar (University, Telkom 2019).

Lobster yang dipasarkan dari beberapa Mini Plant PT. Aruna Indonesia, diantaranya yaitu Mini Plant Sorong, Berau, Kota baru, Balikpapan dan Kendari. Dari kelima Mini Plant tersebut, Mini Plant Kota
Baru, Kalimantan Selatan merupakan Mini Plant yang paling produktif mengirimkan lobster terutama pada saat COVID-19. Lobster hidup sangat di hargai sebagai menu yang berkualitas tinggi di dunia dan kualitas ini merupakan kunci utama bagi usaha perikanan lobster khususnya bagi jenis yang dijual hidup (Asri, 2001).

Revolusi industri 4.0, dunia seolah menjadi tanpa batas. Manusia disuguhi dengan berbagai kemudahan hingga semakin banyaknya muncul platform ecommerce. PT Aruna Jaya Nuswantara adalah salah satu perusahaan yang memanfaatkan teknologi sebagai platform untuk mengembangkan produk digital ecommerce, produk yang dipasarkan yaitu Sea Food By Aruna yang terdapat berbagai produk-produk pilihan Aruna langsung dari nelayannelayan lokal di berbagai wilayah Indonesia dan ditangkap dengan cara-cara yang ramah lingkungan. Sistem penjualan yang diterapkan oleh Aruna ini yaitu sistem ecommerce. Memiliki visi untuk memberikan solusi efesiensi pada mata rantai tata niaga perikanan yang begitu panjang untuk menciptakan perdagangan yang berkeadilan dan transparan.

Kendala implementasi ecommerce di Indonesia utamanya mencakup dua hal yaitu kendala 
yang bersifat teknis dan kendala non teknologi. Kendala teknis seperti belum adanya standar baku yang mengatur mengenai mutu $e$ commerce, keamanan dan kehandalan sistem yang dibangun, masalah bandwidth, dan spesifikasi web server, khususnya dalam menangani masalah jaringan. Kendala dari segi non teknologi di antaranya belum adanya peraturan pemerintah yang mengatur mengenai transaksi perdagangan melalui $e-$ commerce, adanya persepsi bahwa e-commerce tidak aman dan mahal, dan sikap pelaku usaha yang menunggu kondisi e-commerce menjadi stabil sebelum ikut berpartisipasi. Untuk mengantisipasi kendala-kendala tersebut, pemerintah Indonesia dapat mengambil pengalaman penyelenggaraan e-commerce di negara Amerika Serikat yang melihat kegiatan e-commerce sebagai kegiatan yang bersifat universal, yang dalam perencanaan pembangunannya akan mengikutsertakan pelaku-pelaku bisnis dalam e-commerce dan membuat peraturan dan insentif bagi perusahaan UKM sehingga dapat tumbuh menjadi perusahaan yang besar (Firmansyah, 2018).

Tujuan penelitian adalah mengidentifikasi tahapan masalah dan menganalisa penyelesaian masalah penjualan lobster (Panulirus spp), dari Mini Plant Kota Baru di PT Aruna Jaya Nuswantara.

\section{BAHAN DAN METODE}

Penelitian dilaksanakan selama satu bulan yaitu pada tanggal 04 Januari s/d 04 Februari 2020 di PT. Aruna Jaya Nuswantara Indonesia, Kota Jakarta Selatan, Daerah Khusus Ibukota Jakarta. Data yang digunakan pada praktek magang ini adalah data primer dan sekunder.

Data primer diperoleh langsung dari wawancara dengan pegawai, serta mengikuti aktivitas dan melibatkan diri secara langsung dalam kegiatan pemasaran.

Tabel 1 Rencana Pengambilan Data Primer Internship Program

\begin{tabular}{|c|c|c|c|c|}
\hline No & Jenis Kegiatan & Teknik & Alat dan Bahan & Output \\
\hline 1. & $\begin{array}{l}\text { Mengamati dan } \\
\text { mengikuti proses } \\
\text { penanganan } \\
\text { lobster serta } \\
\text { mengidentifikasi } \\
\text { permasalahan } \\
\text { yang terjadi }\end{array}$ & $\begin{array}{l}\text { Wawancara } \\
\text { Observasi } \\
\text { Praktik } \\
\text { langsung } \\
\text { Dokumentasi }\end{array}$ & $\begin{array}{l}\text { Alat } \\
\text { Form pengamatan } \\
\text { proses dan identifikasi } \\
\text { masalah setiap tahapan } \\
\text { proses, Alat tulis, } \\
\text { Handphone, } \\
\text { Perlengkapan praktik }\end{array}$ & $\begin{array}{l}\text { Data kegiatan proses } \\
\text { penanganan lobster di } \\
\text { setiap tahapan } \\
\text { Data identifikasi masalah } \\
\text { di setiap tahapan proses }\end{array}$ \\
\hline
\end{tabular}




\begin{tabular}{|c|c|c|c|c|}
\hline & & & $\begin{array}{l}\text { Bahan penanganan } \\
\text { lobster yang disediakan } \\
\text { oleh nelayan dan mitra } \\
\text { Aruna }\end{array}$ & \\
\hline \multirow[t]{4}{*}{2.} & \multirow{4}{*}{$\begin{array}{l}\text { Melakukan } \\
\text { intervensi } \\
\text { terhadap } \\
\text { permasalahan } \\
\text { yang terjadi }\end{array}$} & \multirow{4}{*}{$\begin{array}{l}\text { Praktik } \\
\text { Langsung } \\
\text { Dokumentasi }\end{array}$} & Alat: & \multirow{4}{*}{$\begin{array}{l}\text { Data efesiensi dan } \\
\text { efektifitas intervensi untuk } \\
\text { mengatasi masalah yang } \\
\text { terjadi }\end{array}$} \\
\hline & & & $\begin{array}{l}\text { disesuaikan dengan } \\
\text { intervensi, Form hasil uji } \\
\text { coba intervensi, } \\
\text { Handphone dan Alat tulis }\end{array}$ & \\
\hline & & & Bahan: & \\
\hline & & & $\begin{array}{l}\text { Bahan praktik yang } \\
\text { disesuaikan dengan } \\
\text { intervensi }\end{array}$ & \\
\hline
\end{tabular}

Data sekunder adalah data yang diperoleh secara tidak langsung yang dikumpulkan dari beberapa pihak dan sumber-sumber yang berkaitan dengan PT Aruna Jaya Nuswantara, Kota Jakarta Selatan, Daerah Khusus Ibukota Jakarta, diantaranya mitra Aruna dan customer Aruna.

Menurut Putri dan Handayani (2015), metode yang digunakan pada teknik permasalahan yaitu menentukan Key Performance Indicator, Fishbone Diagram, Analisa Root Cause dan Rencana Penerapan Intervensi.

\section{HASIL DAN PEMBAHASAN}

\section{Hasil}

Distribusi Lobster

Pada transportasi dengan menerapkan suhu rendah dan lingkungan yang cukup lembab, lobster air tawar dapat bertahan hingga lebih dari 48 jam. Jika penanganan dan teknik transportasi yang diberikan tidak sesuai, maka dapat menyebabkan tingkat kematian lobster selama transportasi menjadi tinggi. Agar derajat kelulusan hidup lobster tetap tinggi setelah sampai ke tempat tujuan, maka lobster harus dikondisikan dalam aktivitas dan metabolisme rendah. Semakin lama lobster bertahan hidup maka akan semakin luas jangkauan distribusinya. Pada dasarnya dalam transportasi ikan hidup, suhu rendah merupakan faktor yang sangat penting untuk menentukan tingkat kelulusan hidup selama transportasi (Berka, 1986).

Hasil penelitian Suryaningrum et al, (2007), memberikan informasi mengenai perubahan fisiologis lobster air tawar pada berbagai suhu. Informasi tersebut digunakan untuk menentukan suhu imotil/shock dan suhu media selama transportasi. Adapun respon fisiologis terhadap penurunan suhu yang dilakukan secara bertahap dapat dilihat pada Tabel 2. 
Tabel 2 Respon aktivitas fisiologi lobster air tawar pada berbagai suhu

\begin{tabular}{|c|c|c|c|}
\hline No & Suhu $\left({ }^{\circ} \mathrm{C}\right)$ & Perubahan Aktivitas & Kriteria \\
\hline 1. & $30,4-25,4$ & $\begin{array}{l}\text { Pada suhu ini lobster bergerak aktif, kaki jalan, kaki } \\
\text { renang, dan chelliped (capit) bergerak aktif, lobster } \\
\text { cenderung bergerombol }\end{array}$ & Aktivitas normal \\
\hline 2. & $25,4-19,4$ & $\begin{array}{l}\text { Aktivitas lobster mulai berkurang, kaki jalan, kaki } \\
\text { renang dan chelliped bergerak perlahan-lahan, ekor } \\
\text { melipat ke dalam, lobster cenderung diam }\end{array}$ & Tenang \\
\hline 3. & $19,6-15,4$ & $\begin{array}{l}\text { Lobster gelisah, } 1-2 \text { ekor bergerak tidak beraturan } \\
\text { dengan menyentak-nyentakan tubuhnya mundur } \\
\text { kebelakang. Setelah panik lobster }\end{array}$ & Panik \\
\hline 4. & $15,4-12,9$ & $\begin{array}{l}\text { Lobster mulai hilang keseimbangan, gerakan lobster } \\
\text { lemah, respon terhadap rangsangan lemah, ketika } \\
\text { posisi tubuh dibalik tidak dapat tegak kembali }\end{array}$ & Awal disorientasi \\
\hline 5. & $12,9-10,4$ & $\begin{array}{l}\text { Lobster hilang keseimbangan, posisi tubuh } \\
\text { rebah/terbalik, kaki jalan dan kaki renang diam }\end{array}$ & Disorientasi \\
\hline 6. & $10,4-9,8$ & $\begin{array}{l}\text { Keseimbangan lobster tidak ada, posisi tubuh } \\
\text { terbalik, kaki jalan, kaki renang dan chelliped kaku } \\
\text { tidak bergerak, ekor melipat ke arah abdomen. } \\
\text { Respon terhadap rangsangan tidak ada }\end{array}$ & Pingsan \\
\hline
\end{tabular}

Suhu kemasan yang optimum untuk transportasi lobster sebaiknya berkisar antara $15-20^{\circ} \mathrm{C}$, pada suhu ini lobster dalam kondisi tenang, sehingga aktivitas lobster tidak banyak bergerak. Suhu kemasan juga tidak boleh terlalu dingin atau kurang dari $12^{\circ} \mathrm{C}$, jika lobster berada pada suhu terlalu dingin dalam jangka waktu yang lama maka lobster akan mengalami eklamsia yang dapat menyebabkan kematian (Suryaningrum et al, 2007)

Tabel 3 Data Penjualan Lobster Hidup

\begin{tabular}{llllll}
\hline \multirow{2}{*}{ Bulan } & \multicolumn{4}{c}{ Komoditi Lobster (kg) } & \multirow{2}{*}{$\begin{array}{c}\text { Total Lobster } \\
\text { (kg) }\end{array}$} \\
\cline { 2 - 5 } & Mutiara & Bambu & Pakistan & Lainnya & \multicolumn{1}{c}{ Pamb } \\
\hline Desember 2020 & 92,904 & 67,968 & 61,824 & 36,144 & 258,84 \\
Januari 2021 & 43,824 & 73,728 & 141,372 & 42,66 & 301,584 \\
\hline
\end{tabular}

Berdasarkan tabel diatas, data penjualan lobster hidup dari beberapa jenis komoditi lobster (Mutiara, Bambu, Pakistan dan lainnya) yang terdapat pada bulan
Desember 2020 total lobster yang dijualkan yaitu sebanyak 258,84 kg, dan total lobster pada bulan Januari sebesar mengalami kenaikan sebesar $301,584 \mathrm{~kg}$. 
Tabel 4 Total Komponen Biaya Modal

\begin{tabular}{lll}
\hline Handling & $10.000 / \mathrm{kg}$ & Artinya pada setiap proses distribusi \\
Logistik & $35.000 / \mathrm{kg}$ & mengalami biaya modal sebesar \\
\cline { 1 - 2 } Berdasarkan & data diatas & \\
45.000/kg pada lobster.
\end{tabular}

biaya modal pada handling yaitu $10.000 / \mathrm{kg}$ dan logistik 35.000/kg.

menunjukkan bahwa total komponen

Tabel 5 Total Penjualan Sea Food By Aruna Lobster Beku

\begin{tabular}{cccccccccc}
\hline \multirow{2}{*}{$\begin{array}{c}\text { Month/Siz } \\
\mathbf{e}\end{array}$} & \multicolumn{2}{c}{ 200up } & \multicolumn{2}{c}{ 500up } & \multicolumn{2}{c}{ 800up } & \multicolumn{2}{c}{ Total Lobster } \\
\cline { 2 - 10 } & $\begin{array}{c}\text { Masu) } \\
\mathbf{k}\end{array}$ & $\begin{array}{c}\text { Kelua } \\
\mathbf{r}\end{array}$ & $\begin{array}{c}\text { Masu } \\
\mathbf{k}\end{array}$ & $\begin{array}{c}\text { Kelua } \\
\mathbf{r}\end{array}$ & $\begin{array}{c}\text { Masu } \\
\mathbf{k}\end{array}$ & $\begin{array}{c}\text { Kelua } \\
\mathbf{r}\end{array}$ & $\begin{array}{c}\text { Masu } \\
\mathbf{k}\end{array}$ & $\begin{array}{c}\text { Kelua } \\
\mathbf{r}\end{array}$ \\
\hline Desember & 148 & 127,5 & 146,5 & 142 & 44,9 & 29,4 & 339,4 & 298,9 \\
Januari & 70,5 & 57 & 54,5 & 31,6 & 69,5 & 43,5 & 194,5 & 132,1 \\
\hline
\end{tabular}

Manfaat dari e-commerce

Hasil diatas dapat dilihat bahwa total penjualan Sea Food By Aruna lobster beku pada bulan Desember 2020 yang masuk sebesar $339,4 \mathrm{~kg}$ sedangkan yang keluar yaitu sebesar 298,9 dan pada bulan Januari 2021 total lobster pada bulan Desember 2020 yang masuk sebesar 194,5 sedangkan yang keluar yaitu $132,1 \mathrm{~kg}$.

Lobster hasil tangkapan dari nelayan dapat didistribusikan dan dipasarkan dalam bentuk frozen melalui beberapa e-commerce yaitu Tokopedia, Lazada, Shopee, Belibeli, Grab Mart dan Sayur Box yang terdapat di Distribution Center Aruna dengan produk Sea Food By Aruna. Aruna Indonesia menggunakan beberapa e-commerce cenderung ingin mendapatkan pemasaran yang efektif dan efisien sebagai sarana informasi dalam transaksi. bagi konsumen Aruna diantaranya

dapat melayani transaksi 24 jam hampir disetiap lokasi, memberikan banyak pilihan produk pada pelanggan, menyediakan produk yang tidak mahal dengan cara mengunjungi banyak tempat dan melakukan pembandingan secara tepat, pengiriman menjadi cepat, partisipasi dalam pelayanan maya (virtual action), dapat berinteraksi dengan pelanggan lain, memudahkan persaingan dan banyak terdapat promo pada produk Sea Food. Menurut Medah (2016), dengan adanya e-commerce diharapkan perusahaan lebih berperan aktif menggunakan media e-commerce sebagai sarana promosi yang tepat dalam pemasaran akan suatu produk.

\section{Pemasaran Lobster}


Analisis Kaizen dalam Meningkatan Produktivitas Penjualan Lobster Hidup

(Panulirus Spp) di PT. Aruna Jaya Nuswantara Jakarta

Berikut tabel harga lobster Desember 2020 - Januari 2021

untuk ukuran 200-500 gr pada

Tabel 6 Harga Rata-Rata Penjualan Lobster

\begin{tabular}{lllll}
\hline Harga Rata-rata Penjualan & Mutiara & Bambu & Pakistan & Lainnya \\
\cline { 2 - 5 } & 800.000 & 400.000 & 400.000 & 350.000 \\
\hline
\end{tabular}

Berdasarkan tabel diatas dapat dilihat bahwa harga lobster tertinggi yaitu jenis lobster mutiara, hal ini dikarenakan lobster jenis mutiara ini memiliki ukuran yang sangat besar dan memiliki rasa daging yang tebal dan lebih enak.

\section{DIAGRAM ALIR DISTRIBUSI DAN PEMASARAN LOBSTER}

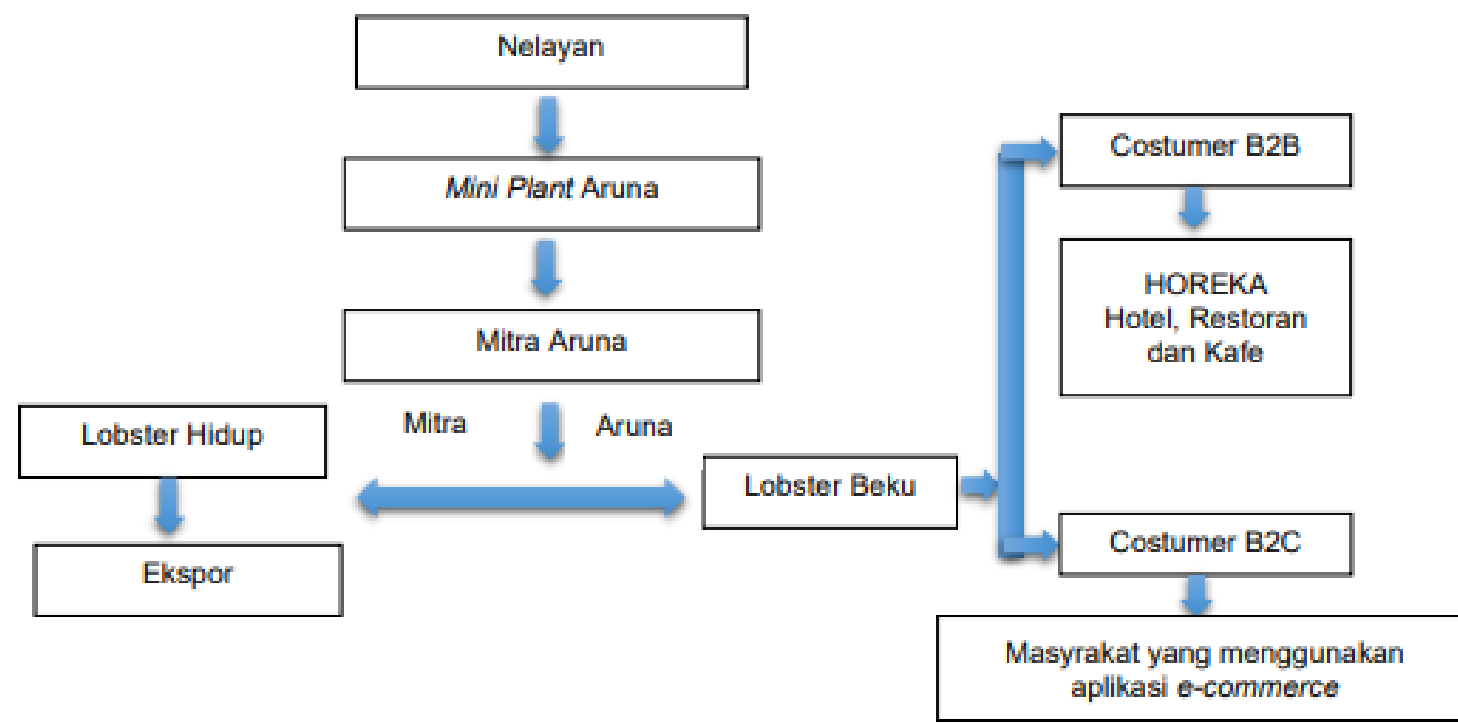

Pada gambar 1 menunjukan disortasi dan diperiksa terlebih dahulu bahwa titik kritis pada distibusi dan pemasaran terjadi pada pengiriman ke mitra aruna yang sebelumnya lobster yang dikirim keluar pulau dari miniplant Kelautan dan Perikanan Kabupaten Kota Kota Baru, Kalimantan Selatan yang Baru, Kalimantan Selatan. akan dikirim sampai di cargo akan 
Analisa Key Performance Indicator (KPI)

Penjualan Lobster

Lobster telah menjadi suatu komoditas bahan pangan yang telah menjadi primadona masyarakat dunia dan memiliki nilai ekonomis yang tinggi. Alasan tersebutlah yang menyebabkan adanya penanganan lobster. Lobster dapat dikirim dengan keadan hidup, sehingga tingkat kesegaran lobster tetap terjaga hingga sampai ke tangan konsumen.

Kondisi Fisik Lobster

Kriteria penilaian lobster adalah sebagai berikut:

1. Lobster yang sehat ciri-cirinya yaitu anggota tubuh lengkap dan kaki penggerak merespon ketika di Tarik dan buntut juga merespon aktif.

2. Lobster yang loyo ciri-cirinya yaitu anggota tubuh lengkap kaki penggerak tidak merespon aktif terlihat sangat lemah saat ditarik dan dapat dicegah dengan melakukan karantina.

3. Lobster yang mati ciri-cirinya yaitu anggota tubuh tidak ada yang merespon jika di sentuh maupun di tarik dan bau sudah tidak fresh/ anyir.

4. Lobster yang cacat ciri-cirinya yaitu anggota tubuh tidak lengkap atau terlepas pada saat pengiriman karena stress dan daging nya terlepas dari cangkang.

5. Lobster yang moulting ciri-cirinya yaitu anggota tubuh lengkap, untuk kulit di bagian karapas biasanya lembek karena sudah berganti kulit, biasanya lobster cepat mati ketika sampai tujuan, dan disarankan untuk di refreshment \pm 14 hari.

6. Lobster yang bertelur, dalam upaya mencegah terjadi nya penjualan lobster bertelur, yang mengacu pada pelarangan PERMEN-KP NO $56 / 2016$ tentang pelarangan penangkapan atau pengeluaran lobster (Panulirus sppp), rajungan (Portunus spp), dan kepiting (Scylla spp). Tentunya Kementrian Kelautan dan Perikanan menegaskan apabila ada suatu individu atau perusahaan memperjual belikan benih Kepiting, Rajungan, dan Lobster endemic Indonesia akan diberi sanksi hukuman 2 Tahun penjara dan denda maksimal 2 miliar (Peraturan Menteri Kelautan dan Perikanan Republik Indonesia, 2016)

Namun, pengirimin lobster hidup memiliki kendala yang banyak ketika dilakukan proses pengiriman. Kendala tersebut seperti jarak yang jauh untuk pengiriman, kelembapan yang selalu terjaga agar lobster tetap hidup, dan metabolisme yang ditekan rendah dengan suhu rendah yang tetap optimal. Banyaknya kendala dapat diatasi dengan teknologi yang memadai.

Beberapa keunggulan ecommerce dapat dipegang oleh perusahaan yang tidak memaksakan kekuatan potensialnya dengan memahami keunggulan perdagangannya untuk konsumen maupun untuk dunia 
bisnis (Medah, 2016).

Tabel 7 KPI (Key Performance Indicator) Pengiriman Lobster

\begin{tabular}{lll}
\hline No & \multicolumn{1}{c}{ Komponen } & \multicolumn{1}{c}{ Keterangan } \\
\hline 1 & Persentasi Margin Keuntungan & $\begin{array}{l}\text { Lobster Mutiara Minimal 25\% } \\
\text { Lobster Jenis lainnya Minimal 10\% }\end{array}$ \\
2 & Mortality Rate (Tingkat Kematian) & Maksimal 5\% \\
3 & Biaya Handling & $7.000-10.000 / \mathrm{kg}$ \\
4 & Biaya Logistik & $30.000-35.000 / \mathrm{kg}$ \\
5 & dll & Tidak mengirim lobster bertelur/moulting \\
\hline
\end{tabular}

Berdasarkan tabel diatas menunjukkan bahwa kemampuan pengiriman lobster pada PT Aruna dengan persentasi margin keuntungan pada lobster mutiara minimal $25 \%$ dan lobster jenis lainnya minimal $10 \%$, tingkat kematian di maksimal $5 \%$, biaya handling maksimal 10.000/kg, biaya logistik maksimal $35.000 / \mathrm{kg}$ dan tidak mengirimkan lobster bertelur/moulting sesuai dengan PERMEN KP No.1/PERMEN$\mathrm{KP} / 2015$.

\section{Analisa Diagram Fishbone}

\section{Analisa Root Cause}

Analisa root cause dilakukan untuk proses identifikasi sebabakibat utama suatu permasalahan dengan menggunakan pendekatan yang terstruktur analisa root cause proses terhadap penjualan lobster yang belum maksimal. 


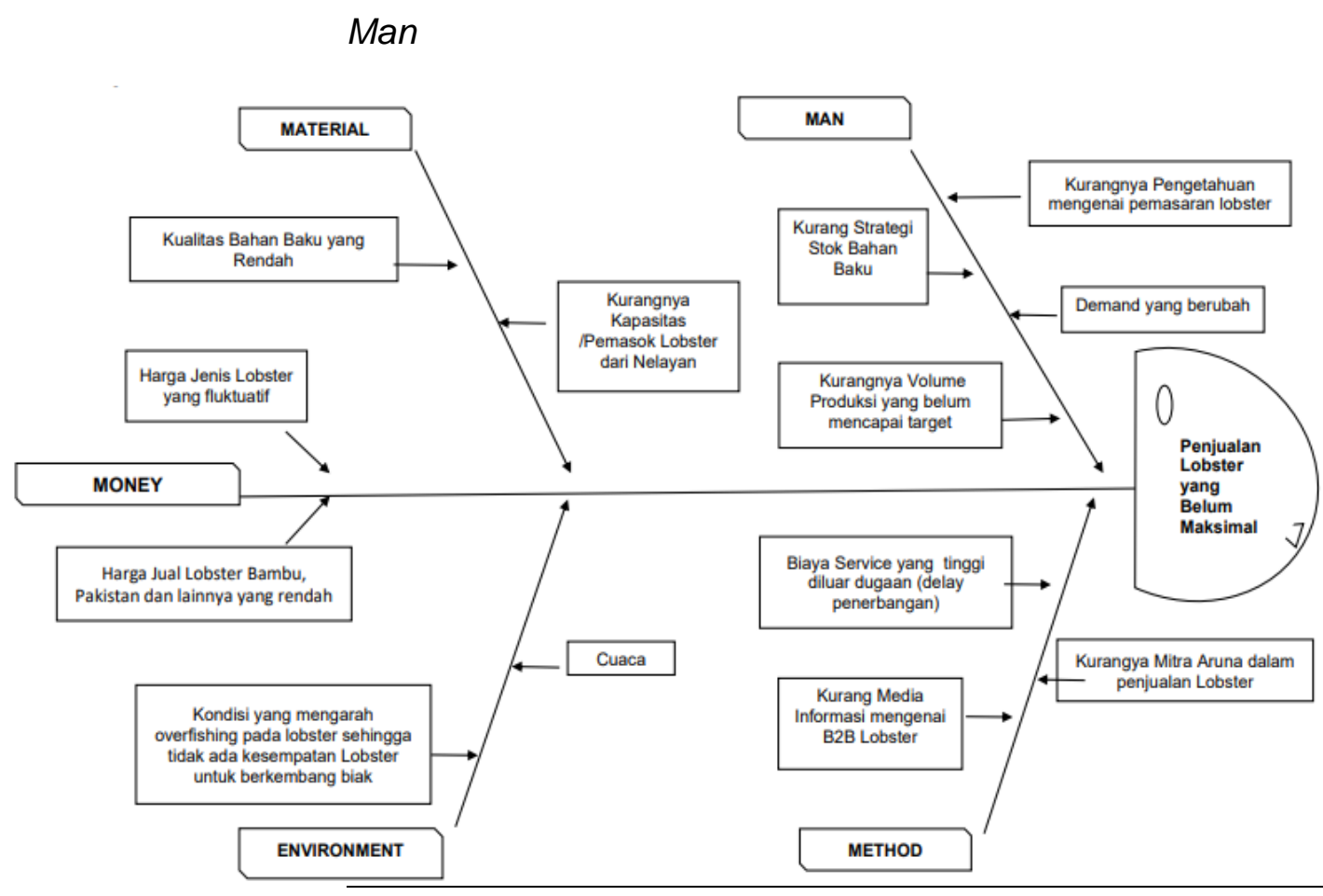

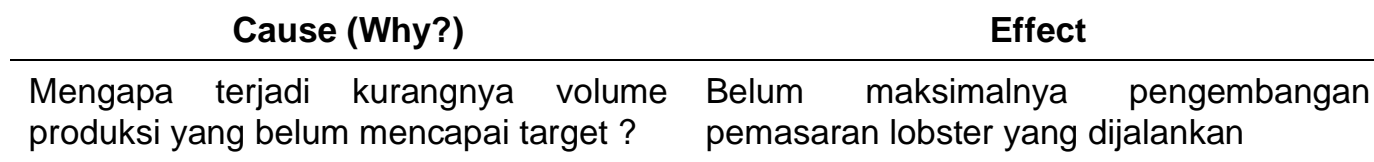

Mengapa belum maksimalnya Belum meningkatnya volume penjualan pengembangan pemasaran lobster yang lobster dengan memiliki pasar yang luas dijalankan? agar mampu bersaing dengan usaha yang sejenis

\section{Method}

\section{Cause (Why?)}

Mengapa terjadi adanya kurangnya mitra Aruna dalam penjualan lobster?

Mengapa belum maksimalnya pemasok Lobster dari Nelayan sehingga Aruna belum banyak mitra?

Mengapa belum ada pegoptimalan Nelayan sebagai pemasok yang rutin untuk memenuhi permintaan yang cenderung naik?

Mengapa belum ada sistem baku untuk distribusi pemasaran hasil lobster, yaitu perusahaan belum menentukan strategi pemasaran kepada mitra-mitra untuk meningkatkan omzet/ keuntungan perusahaan?

\section{Effect}

Belum maksimalnya pemasok Lobster dari Nelayan sehingga Aruna belum banyak mitra yang bekerjasama

Belum mengoptimalkan Nelayan sebagai pemasok yang rutin untuk memenuhi permintaan yang cenderung naik

Belum ada sistem baku untuk distribusi pemasaran hasil lobster, yaitu perusahaan belum menentukan strategi pemasaran kepada mitra-mitra untuk meningkatkan omzet atau keuntungan perusahaan

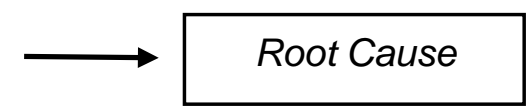


Material

\begin{tabular}{l} 
Cause (Why?) \\
\hline Mengapa terjadi kualitas bahan baku \\
lobster yang rendah? \\
Mengapa belum meningkatkan pasokan \\
lobster dan menjaga mutu agar harga dan \\
permintaan tetap tinggi?
\end{tabular}

Belum menjalin kerjasama dengan pemerintah Kota Baru dalam hal informasi perluasan distribusi pemasaran, sehingga pelanggan semakin meningkat dan dengan sendirinya pendapatan pun semakin meningkat

Belum meningkatkan pasokan lobster dan menjaga mutu agar harga dan permintaan tetap tinggi

Mengapa belum menjalin kerjasama dengan pemerintah Kota Baru dalam hal informasi perluasan distribusi pemasaran, sehingga pelanggan semakin meningkat

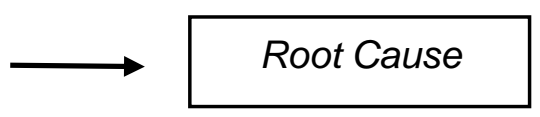
dan dengan sendirinya pendapatan pun semakin meningkat?

\section{Money}

\section{Cause (Why?)}

Mengapa terjadi harga jenis lobster yang fluktuatif?

Mengapa belum menunjukan keadaan atau kondisi yang tidak tetap atau berubah-ubah pada harga jenis lobster?

Mengapa belum terdapat hasil tangkapan yang stabil sehingga komoditi tidak tentu dan harga berubah-ubah?

\section{Effect}

Belum menunjukan keadaan atau kondisi yang tidak tetap atau berubah-ubah pada harga jenis lobster

Belum terdapat hasil tangkapan yang stabil sehingga komoditi tidak tentu dan harga berubah-ubah

\section{Environment}

\section{Cause (Why?)}

Mengapa cuaca menjadi kendala dalam penjualan lobster?

Mengapa faktor alam, seperti gelombang tinggi dan angin barat, sehingga seringkali aktivitas penangkapan ikan terganggu dan terhenti dalam beberapa saat menjadi pengaruh?

\section{Effect}

Dipengaruhi oleh faktor alam, seperti gelombang tinggi dan angin barat, sehingga seringkali aktivitas penangkapan ikan terganggu dan terhenti dalam beberapa saat.

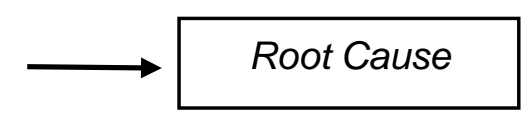


Analisis Penerapan Intervensi

Penerapan intervensi

terhadap permasalahan produktivitas

pada penjualan Lobster di Aruna

Indonesia dilakukan berdasarkan

waktu, sarana prasarana serta kemampuan dalam

mengaplikasikannya. Penerapan

intervensi di tinjau dari akar

permasalahan yang didapat serta

kemungkinan untuk melakukan

perbaikan berdasarkan pengamatan.

Tabel 8 Penerapan Usulan Intervensi

\section{Jenis Permasalahan}

Belum meningkatnya volume penjualan lobster dengan memiliki pasar yang luas agar mampu bersaing dengan usaha yang sejenis.

Belum ada sistem baku untuk distribusi pemasaran hasil lobster, yaitu perusahaan belum menentukan strategi pemasaran kepada mitramitra untuk meningkatkan omzet/ keuntungan perusahaan.

\section{Strategi/Usulan Perbaikan}

Untuk meningkatkan volume penjualan lobster harus menentukan sistem distribusi pemasaran atau strategi pemasaran untuk memenuhi permintaan yang cenderung sering kali naik, dengan berdasarkan dukungan dari pemerintah, sehingga pengelolaan lobster bisa maksimal dengan adanya sistem distribusi pemasaran di Aruna, maka perusahaan bisa mengoptimalkan adanya permintaan yang cenderung naik dengan dukungan dari pemerintah Kota Baru

Menjaga hubungan yang baik antara aruna dengan para nelayan dan pentingnya membina hubungan yang baik dengan konsumen akan pentingnya pasar, sehingga mitra Aruna tetap terjalin dengan baik dalam hal ini masyarakat sebagai konsumen.

Bekerjasama dengan mitra-mitra baru/ buyer, dengan begitu akan membuka kesempatan mendapatkan keuntungan yang menjanjikan, terutama dengan melakukan kegiatan ekspor sendiri tanpa melibatkan mitra-mitra, hal tersebut dapat memutus tali rantai pasok terhadap lobster dan akan mendapatkan keuntungan yang meningkat. Mencari buyer yang baru sebagai buyer yang kuantitas permintaannya selalu dalam jumlah besar dan kontinu.

Belum menjalin kerjasama dengan pemerintah Kota Baru dalam hal informasi perluasan distribusi pemasaran, sehingga pelanggan semakin meningkat dan dengan sendirinya pendapatan pun semakin meningkat

Mengapa belum terdapat hasil tangkapan yang stabil sehingga komoditi tidak tentu dan harga berubah-ubah
Menjalin kerjasama dengan pemerintah Kabupaten Kota Baru dalam hal informasi perluasan distribusi pemasaran, sehingga pelanggan semakin meningkat dan dengan sendirinya pendapatan pun semakin meningkat. Pemerintah dalam hal memperluas distribusi pemasaran lobster. Dengan adanya campur tangan pemerintah Kota Baru yang sudah mengetahui pemasaran Aruna yang baik dengan meningkatkan harga beli dari nelayan Kota Baru dibandingkan dengan yang lainnya dalam hal ini dapat memperluas distribusi lobster, para nelayan akan menjualkan hasil tangkapannya kepada Aruna saja agar lobster lebih mudah dipasarkan dengan harga yang relatif tinggi.

Peningkatan SDM pada nelayan yang berkualitas Sumberdaya manusia yang dimiliki masih sangat kurang, sehingga proses penangkapan pembudidayaan agak sedikit, selain itu juga perlu ditunjang dengan keterampilan dalam membudidaya lobster dalam hal ini memberikan edukasi bagaimana cara penangkapan lobster yang baik sehingga ekosistem lobster yang baru tidak terganggu dan tidak terjadi 
penagkapan yang berlebihan atau overfishing, sehingga harga akan lobster cenderung stabil dan tidak fluktuatif.

Faktor alam, seperti gelombang tinggi dan angin barat, sehingga seringkali aktivitas penangkapan ikan terganggu dan terhenti dalam beberapa saat menjadi pengaruh
Melakukan strategi stok bahan baku lobster dengan menambah volume bahan baku (lobster) agar memenuhi permintaan pasar untuk mengantisipasi pengaruh faktor alam yang terjadi yang tidak dapat di prediksi sewaktu-waktu agar penjualan lobster stabil.

Dengan menambah tersedianya sarana seperti kolam refreshment di miniplant dalam pengembangan usaha lobster atau dengan kata lain memaksimalkan kualitas serta potensi yang dimiliki Aruna untuk menghadapi tingkat persaingan yang tinggi serta mengantisipasi adanya ancaman faktor alam yang seringkali tidak mendukung, maka perlu bagi Aruna untuk mengantisipasi hal tersebut dengan memaksimalkan kualitas atau potensi perusahaan untuk menghadapi tingkat persaingan yang tinggi dengan melakukan strategi stok bahan baku.

Persediaan bahan baku berlebih atau overstock sangat merugikan perusahaan, hal ini juga menyebabkan keuntungan perusahaan yang menjadi berkurang akibat biaya yang di munculkan semakin tinggi. Apabila hal ini terjadi, dampaknya tidak hanya pada keuntungan saja yang akan berkurang, akan tetapi juga akan memunculkan biaya-biaya lainnya diantaranya biaya penyimpanan bahan baku dan biaya perawatan bahan baku (Indriyani and Budiawan. 2018).

\section{Analisa Kuadran Intervensi}

\section{Mendesak}

Tidak Mendesak

\begin{tabular}{|c|c|c|}
\hline & Mendesak & Tidak Mendesak \\
\hline & $\begin{array}{l}\text { Kuadran I } \\
\text { Melakukan strategi stok bahan baku } \\
\text { lobster }\end{array}$ & $\begin{array}{l}\text { Kuadran II } \\
\text { Menjaga hubungan yang baik } \\
\text { antara aruna dengan para nelayan. }\end{array}$ \\
\hline Penting & $\begin{array}{l}\text { Meningkatan SDM pada nelayan dengan } \\
\text { memberikan edukasi bagaimana cara } \\
\text { penangkapan lobster yang baik sehingga } \\
\text { ekosistem lobster yang baru tidak } \\
\text { terganggu dan tidak terjadi penagkapan } \\
\text { yang berlebihan atau overfishing, } \\
\text { sehingga harga akan lobster cenderung } \\
\text { stabil dan tidak fluktuatif. }\end{array}$ & $\begin{array}{l}\text { Menentukan sistem distribusi } \\
\text { pemasaran atau strategi pemasaran } \\
\text { untuk memenuhi permintaan yang } \\
\text { cenderung sering kali naik, dengan } \\
\text { berdasarkan dukungan dari } \\
\text { pemerintah. }\end{array}$ \\
\hline $\begin{array}{l}\text { Tidak } \\
\text { Penting }\end{array}$ & $\begin{array}{l}\text { Kuadran III } \\
\text { Menjalin kerjasama dengan pemerintah } \\
\text { Kabupaten Kota Baru dalam hal informasi } \\
\text { perluasan distribusi pemasaran, sehingga } \\
\text { pelanggan semakin meningkat dan } \\
\text { dengan sendirinya pendapatan pun } \\
\text { semakin meningkat. }\end{array}$ & $\begin{array}{l}\text { Kuadran IV } \\
\text { Melakukan kegiatan ekspor sendiri } \\
\text { tanpa melibatkan mitra-mitra, hal } \\
\text { tersebut dapat memutus tali rantai } \\
\text { pasok terhadap lobster dan akan } \\
\text { mendapatkan keuntungan yang } \\
\text { meningkat. }\end{array}$ \\
\hline
\end{tabular}




\section{Nilai Produktivitas Penjualan}

Produktivitas penjualan ialah perhitungan produktivitas perusahan dilihat dari segi penjualannya.untuk menghitung produktivitas penjualan maka nilai laba kotor di bagi dengan biaya penjualan (Syarifuddin dan Lisa Yani, 2014).

Dapat disimpulkan bahwa tingkat produktivitas dari lobster hidup sudah baik yakni diatas nilai 1 yang artinya jika kurang dari 1 adanya mengalami kerugian, namun perlu adanya peningkatan untuk mencapai kpi yang telah ditetapkan, maka dari itu perlu di analisis intervensinya.

\section{Pembahasan}

Salah satu komoditas perikanan Indonesia yang sangat potensial untuk dikembangkan adalah lobster (Panulirus spp) bernilai ekonomis tinggi dengan tujuan pemasaran untuk konsumsi local maupun luar negeri (ekspor) (Asri, 2001). Hasil dari penelitian didapatkan proses distribusi lobster pada pelaksanaanya nelayan memberikan hasil tangkapannya kepada Local Hero Aruna di Kota Baru untuk di input berapa banyak lobster yang didapat dari hasil melaut. Total Lobster yang dibeli oleh Aruna kepada Nelayan harus sama dengan Total penjualan yang dipasarkan ke
Mitra Aruna (CV Sea Queen). Agar derajat kelulusan hidup lobster tetap tinggi setelah sampai ke tempat tujuan, maka lobster harus dikondisikan dalam aktivitas dan metabolisme rendah. Semakin lama lobster bertahan hidup maka semakin luas jangkauan distribusinya. Pada dasarnya dalam transportasi ikan hidup, suhu rendah merupakan faktor yang sangat penting untuk menentukan tingkat kelulusan hidup selama transportasi (Berka, 1986).

Proses packing dimulai dengan lobster dilumuri dengan serbuk kayu/jika di pedalaman kesulitan mencari serbuk kayu bisa juga dengan pasir pantai yang kering tidak yang lembab, guna dari dilakukannya treatment ini agar lobster tetap dalam keadaan kering dan tidak lembab karena jika keadaan lobster lembab ketika diperjalanan lobster akan sadar dari biusan sehingga bisa dipastikan bahwa ketika tiba di tujuan lobster sudah banyak yang loyo dan stress akibat guncangan pada saat pengiriman. Fungsi serbuk gergaji yaitu untuk mempertahankan suhu rendah lobster dan mencekal lobster dalam kemasan. Menurut Asri (2001) pada proses pengepakan lobster menggunakan sistem kering yang menggunakan cara pembiusan tanpa menggunakan air. Terlebih dahulu melakukan persiapan berupa penyedian media berupa serbuk 
gergaji dan kotak stryfoam. Serbuk gergaji didinginkan dengan memberi bungkusan es batu selama 30 menit1 jam hingga media serbuk gergajii menjadi dingin. Kotak stryfoam diberi bungkusan es batu secara merata yang kemudian dilapisi serbuk gergaji hingga bungkusan es batu tertutup serbuk gergaji. Lobster yang telah dibius atau dipingsankkan dengan cara memasukkan lobster ke dalam wadah air dingin dengan suhu 10$18^{\circ} \mathrm{C}$ dibungkus dengan koran dan kemudian ditaruh pada kotak stryfoam yang telah dilapisi serbuk gergaji secara merata.

Pada Analisa KPI, diagram fishbone, root cause pada penjualan lobster masih belum maksimal hasilnya jika dilihat berdasarkan data yang anaslis pada bulan Desember dan Januari, karena belum memenuhi KPI yang diterapkan. Tingginya tingkat kematian juga disebabkan adanya efek domino, yaitu apabila dalam kemasan plastik tersebut ada lobster yang mati pada awal penyimpanan, maka kematian tersebut menyebabkan kematian lobster yang lainnya. Lobster yang mati akan mengalami proses pembusukan yang menyebabkan terbentuknya gas-gas seperti amonia, dan $\mathrm{H}_{2} \mathrm{~S}$ yang bersifat toksik. Adanya gas tersebut menyebabkan rusaknya jaringan insang, yang terlihat dari perubahan warna insang menjadi hitam sehingga respirasi lobster terganggu, dan menyebabkan kematian (Suryaningrum et al, 2008). Jika dapat meningkatkan kapasitas produk dengan memanfaatkan harga jual produk yang tinggi sehingga bisa mendapatkan laba yang optimal (Hardi et al, 2017). Pada respon aktifitas aktivitas fisiologi lobster air tawar pada berbagai suhu, bahwa suhu kemasan yang optimum untuk transportasi lobster sebaiknya berkisar antara $15-20^{\circ} \mathrm{C}$, pada suhu iniaktivitas lobster mulai berkurang, kaki jalan, kaki renang dan cheliped bergerak perlahan-lahan, ekor melipat ke dalam, lobster cenderung diam dan pada suhu ini lobster dalam keadaan kondisi yang tenang.

Jenis-jenis lobster hidup yang terjual pada PT Aruna total lobsternya mengalami kenaikan dari bulan Desember 2020 sebanyak 258,84 kg ke bulan Januari 2021 sebanyak $301,584 \mathrm{~kg}$, yang artinya keuntungan yang diperoleh pun lebih banyak. Menurut (Zulham, 2016), pada penelitiannya mengenai bisnis lobster di Simeulue yaitu tingginya permintaan Lobster tersebut menyebabkan nelayan menangkap Lobster yang tidak diizinkan oleh Peraturan Menteri Kelautan dan Perikanan No. 1 Tahun 2015. Volume Lobster yang ditangkap ukuran <2 gram dan bertelur di Simeulue masih 
tinggi. Dan untuk menyelamatkan potensi tersebut diperlukan inovasi budidaya agar Lobster yang tidak sesuai aturan tersebut tidak diperdagangkan dan dapat dibesarkan dan dipelihara untuk menopang perekonomian masyarakat.

Informasi yang didapat dari dari lapangan bahwa total komponen biaya modal untuk pengiriman lobster dari biaya handling sebesar $10.000 / \mathrm{kg}$ dan logistik sebesar $35.000 / \mathrm{kg}$ dengan total pada setiap distribusi pengiriman lobster yaitu sebesar 45.000/kg pada lobster, maka jumlah tersebutlah yang akan dikeluarkan oleh PT Aruna dalam setiap pendistribusian (kg). Berdasarkan hasil yang didapat dari tabel 5 pada penjualan Sea Food By Aruna mengalami penurunan pada bulan Desember 2020 ke bulan Januari 2021 dikarenakan pada akhir tahun perusahaan melakukan stop opname. Sedangkan pada tabel 6 harga rata-rata penjualan lobster yaitu Lobster mutiaralah yang paling tinggi rata-rata penjualannya karena banyak diburu nelayan meskipun sulit ditangkap karena habitatnya di wilayah perairan yang berombak besar. Harga lobster akan lebih mahal jika dalam keadaan hidup dan masih memiliki bagian tubuh yang lengkap. Harga lobster dapat berubah-ubah/fluktuatif sesuai dengan keadaan yang terjadi selama proses ekspor itu sendiri. Dari penelitian Hardi et al. (2017) mengenai usaha perdangangan lobster laut di CSQ Kota Kendari harga jual lobster jenis Mutiara juga yang harganya paling tinggi disbanding jenis lobster lainnya.

Berdasarkan tabel 7 dapat dilihat bahwa KPI (Key Performance Indicator) pengiriman lobster yang telah diturunkan akan menghasilkan indikator-indikator pengukuran kinerja. penentuan indikator KPI yang diperoleh dari hasil observasi dengan wawancara secara langsung kepada Manager Operasional dan Quality Control (QC) di PT Aruna. Menurut Haris dan Pramudita (2018) pencapaian kinerja perusahaan harus selalu dilakukan evaluasi secara berkala. Evaluasi tersebut merupakan penilaian terhadap apa yang didapatkan oleh customer dan akan menjadi bahan pertimbangan terhadap penggunaan jasa pada kemudian hari terhadap pencapaian kinerja. Hasil Analisa KPI penjualan lobster, dapat disimpulkan bahwa masih belum maksimal dalam penjualan lobster setiap bulannya. Karena masih belum memenuhi KPI yang terapkan, berarti terdapat hambatan atau masalah yang terjadi baik dari sisi internal maupun eksternal.

Pada fishbone diagram menurut Jayusman (2018) yaitu dapat mengkaji dan menyepakati 
sebab-sebab yang paling mungkin.

Menetapkan penyebab yang paling mungkin di antara semua sebabsebab dan sub-subnya. Jika ada sebab-sebab yang muncul pada lebih dari satu kategori, kemungkinan merupakan petunjuk sebab yang paling mungkin. Kaji kembali sebabsebab yang telah didaftarkan (sebab yang tampaknya paling memungkinkan) dan tanyakan, "Mengapa ini sebabnya?" Tanyakan "Mengapa?" sampai saat pertanyaan itu tidak bisa dijawab lagi. Kalau sudah sampai ke situ sebab pokok telah terindentifikasi. Lingkarilah sebab yang tampaknya paling memungkin pada fishbone diagram. Hasil yang didapat pada analisa fishbone diagram ini yaitu pada penjualan lobster yang belum maksimal, sehingga akan dicari bagaimana penyelesaian permasalahan.

Menurut Wibowo et al, (2014), Root Cause Analysis (RCA) merupakan suatu metode untuk penyelesaian permasalahan, mencoba mengidentifikasi faktor penyebab dari suatu permasalahan atau kejadian yang tidak diharapkan. Root Cause Analysis merupakan suatu metode untuk membantu menjawab pertanyaan 'apa yang terjadi?', 'bagaimana bisa terjadi?', dan 'mengapa itu terjadi?'. Tujuan utama metode ini adalah untuk mengidentifikasi faktor yang dinyatakan dalam bentuk alami, besaran, lokasi dan waktu akibat dari kebiasaan, tindakan dan kondisi tertentu yang harus diubah untuk menghindari kesalahan yang tidak perlu. Root Cause Analysis dilakukan dengan bantuan fishbone diagram, lalu dilanjutkan dengan why-why analysis. Pada analisis ini dilakukan untuk melihat proses identifikasi sebab-akibat utama yang terdapat pada permasalahan penjualan lobster yang belum maksimal.

Analisis penerapan intervensi menurut Darmawan (2019), tujuan utama dari metode intervensi sosial adalah memperbaiki fungsi sosial orang (individu, kelompok, masyarakat) yang merupakan sasaran perubahan. Kerika fungsi sosial seseorang berfungsi dengan baik, diasumsikan bahwa kondisi sejahtera akan semakin mudah dicapai. Kondisi sejahtera dapat terwujud manakala jarak antara harapan dan kenyataan tidak terlalu lebar. Melalui intervensi sosial, hambatan sosial yang dihadapi kelompok sasaran perubahan akan diatasi. Dengan kata lain, intervensi sosial berupaya memperkecil jarak antara harapan lingkungan dengan kondisi kenyataan klien. Maka daripada itu penerapan intervensi di tinjau dari akar permasalahan yang didapat serta kemungkinan untuk 
melakukan perbaikan berdasarkan pengamatan permasalahan produktivitas pada penjualan lobster di Aruna Indonesia dilakukan berdasarkan waktu, sarana prasarana serta kemampuan dalam mengaplikasikannya.

\section{SIMPULAN DAN SARAN}

\section{Simpunan}

Berdasarkan

hasil pembahasan diatas dapat disimpulkan sebagai berikut:

1. Total penjualan lobster (Panulirus spp), tingkat produktivitas dari lobster hidup sudah baik yakni diatas nilai 1 yang artinya jika kurang dari 1 adanya mengalami kerugian, Namun perlu adanya peningkatan untuk mencapai KPI yang telah ditetapkan, maka dari itu perlu di analisis intervensinya.

2. Analisa KPI penjualan lobster, dapat disimpulkan bahwa masih belum maksimal dalam penjualan lobster setiap bulannya. Karena masih belum memenuhi KPI yang terapkan, berarti terdapat hambatan atau masalah yang terjadi baik dari sisi internal maupun eksternal.

3. Analisa diagram fishbone yang ditujukan untuk menentukan faktor faktor penyebab permasalahan utama yang menyebabkan produktivitas suatu usaha menurun yaitu mengenai penjualan Lobster yang belum maksimal dengan indikator man, material, method, money dan environment.

4. Analisa root cause untuk proses identifikasi sebab-akibat utama suatu permasalahan dengan menggunakan pendekatan yang terstruktur dalam Analisa root cause dalam penjualan lobster yang belum maksimal.

5. Analisis penerapan intervensi terdapat 5 jenis permasalahan dan sudah terdapat strategi/usulan perbaikan untuk PT Aruna Jaya Nuswantara berdasarkan pengamatan.

\section{Saran}

Berdasarkan hasil pembahasan diatas Adapun saran yang dapat saya diberikan untuk PT Aruna Jaya Nuswantara sebagai berikut:

1. Memaksimalkan kualitas lobster sesuai dengan KPI serta potensi yang dimiliki oleh Aruna untuk menghadapi tingkat persaingan yang tinggi serta mengantisipasi adanya ancaman faktor alam, dengan melakukan strategi stok bahan baku lobster.

2. Membuat kolam refreshment yang sesuai standar dan membuat bak untuk pelumuran serbuk kayu. 
3. Menentukan strategi baru dan memperbanyak mitra Aruna agar meningkatkan penjualan lobster.

4. Menjalin kerjasama dengan pemerintah Kabupaten Kota Baru dalam hal informasi perluasan distribusi pemasaran, sehingga pelanggan semakin meningkat dan dengan sendirinya pendapatan pun semakin meningkat.

\section{PERSANTUNAN}

Penulis mengucapkan terima kasih kepada Founder PT Aruna yaitu Utari Octavianty, Farid Naufal Aslam, dan Indraka Fadhlillah sehingga jurnal ini dapat diterbitkan.

\section{DAFTAR PUSTAKA}

Alma, B. (2011). Manajemen Pemasaran dan Pemasaran Jasa. Alfabeta.

Asri, R. S. (2001). Sistem Pengendalian Mutu Penanganan Lobster (Panulirus sp) Hidup untuk Tujuan Eskspor. IPB Repository.

Berka, R. (1986). The transport of live fish. A review. In Eifac Technical Paper-FAO.

http://www.flyingsharks.eu/litera ture/fao_iata/Transport_of_live_ fish_FAO.pdf

Darmawan, D. (2019). Intervensi sosial. Journal of Chemical Information and Modeling, 53(9),
1689-1699.

Firmansyah, A. (2018). Kajian

Kendala Implementasi ECommerce Di Indonesia. Masyarakat Telematika Dan Informasi: Jurnal Penelitian Teknologi Informasi Dan Komunikasi, 8(2), 127. https://doi.org/10.17933/mti.v8i2 .107.

Hardi, S., Budiyanto, \& Siang, R. D. (2017). Analisis keuntungan dan strategi pengembangan usaha lobster (Panulirus spp. ) Pada CV. Sea Queen Kota Kendari. Jurnal Bisnis Perikanan, 4(1), 37-48.

Haris, R. F., \& Pramudita, A. S. (2018). Analisis Pencapaian Key Performance Indicator Dalam Upaya Perbaikan Kualitas Pelayanan Dengan Pendekatan Difotai (Studi .... Jurnal Logistik Bisnis, 10(2), 37-49. https://ejurnal.poltekpos.ac.id/in dex.php/logistik/article/view/401 Indriyani, M., \& Budiawan, W. (2018). Analisis Penyebab Terjadi Overstock Pada Pt. Hitachi Construction Machinery Indonesia. Industrial Engineering Online Journal, 6(4).

Jayusman. (2018). Analisis "Diagram

Tulang Ikan" untuk Peningkatan Keberhasilan Perbanyakan Vegetatif Makro Surian Putih 
(Toona sureni Merr). 2, 539543.

http://publikasiilmiah.ums.ac.id/ handle/11617/10547

Kotler, P. and K. L. K. (2012). Marketing Management. In Orentice Hall is an imprint of Pearson. Northwestern University. https://doi.org/10.1017/cbo9781 139174749.022

Medah, M. (2016). E-Commerce sebagai pendukung pemasaran perusahaan. 2, 32-42.

Peraturan Menteri Kelautan dan Perikanan Republik Indonesia. (2016). Peraturan Menteri Kelautan dan Perikanan Republik Indonesia Nomor 56/Permen-KP/2016 Tentang Larangan Penangkapan dan/atau Pengeluaran Lobster (Panulirus spp.), Kepiting (Scylla spp.), dan Rajungan (Portunus spp.) Dari Wilayah Negara Republik Indonesia. Kkp Ri, 1-8. Putri, D. A., \& Handayani, N. U. (2015). Pengukuran Kinerja Karyawan Pt. Pertamina (Persero) Tbbm Semarang Group Dengan Pendekatan Human Resources Scorecard. J@Ti Undip: Jurnal Teknik Industri, 10(3), 187-196. https://doi.org/10.12777/jati.10. 3.187-196

Suryaningrum, T. D., Ikasari, D., \& Syamdidi, S. (2008). Pengaruh
Kepadatan dan Durasi dalam Kondisi Transportasi Sistem Kering Terhadap Kelulusan Hidup Lobster Air Tawar (Cherax quadricarinatus). Jurnal Pascapanen Dan Bioteknologi Kelautan Dan Perikanan, 3(2), 171.

https://doi.org/10.15578/jpbkp.v $3 \mathrm{i} 2.22$

Suryaningrum, T. D., Syamdidi, S., \& Ikasari, D. (2007). Teknologi Penanganan dan Transportasi Lobster Air Tawar. Squalen Bulletin of Marine and Fisheries Postharvest and Biotechnology, 2(2), 37. https://doi.org/10.15578/squale n.v2i2.135

Syarifuddin dan Lisa Yani. (2014). Analisis Produktivitas Perusahaan Pada UD . Karya Jaya. Optimasi Sistem Industri, 3(2), 22-27.

University, T. (2019). Gambaran tentang Difusi Inovasi pada Sistem Perdagangan Hasil Laut Rajungan oleh PT. Aruna Jaya Nuswantara di Desa Tanjung Batu Kab. Berau. openlibrary.telkomuniversity.ac.i d

Wibowo, K., Sugiyarto, \& Setiono. (2014). Analisa dan Evaluasi: Akar Penyebab dan Biaya Sisa Material Konstruksi Proyek Pembangunan Kantor Kelurahan di Kota Solo, 
Analisis Kaizen dalam Meningkatan Produktivitas Penjualan Lobster Hidup (Panulirus Spp) di PT. Aruna Jaya Nuswantara Jakarta

Sekolah, dan Pasar

Menggunakan Root Cause

Analysis (RCA) dan Fault Tree

Analysis (FTA). E-Jurnal

MATRIKS TEKNIK SIPIL, 59(9-

10), 303-310.

Wijaya, D. (2018). Pengaruh struktur modal, persistensi laba, kesempatan bertumbuh, rasio likuiditas, dan ukuran perusahaan terhadap earnings response coefficient (studi empiris .... Skripsi-2018, 1-7. http://repository.trisakti.ac.id/we bopac_usaktiana/index.php/ho me/detail/detail_koleksi/0/SKR/j udul/00000000000000094083/0

Zulham, A. (2016). BISNIS LOBSTER DI SIMEULUE: KERAGAAN PERDAGANGAN DAN KEBIJAKAN INOVASI BUDIDAYA Lobster Business in Simeulue : Trade Performed and Cultivation Innovation Policy. 021, 153-164. 